\title{
PERSPEKTIF PSIKOLOGI ISLAMI TENTANG MANUSIA Suatu Pandangan Dașar
}

\author{
Fuad Nashori \\ Universitas Islam indonesia
}

\begin{abstract}
INTISARI
Salah satu tugas terpenting psikologi islami adalah menjelaskan pandangan dasar Islam tentang manusia. Tulisan in bermaksud membentangkan pandangan Islam tentang tujuan penciptaan dan relasi manusia, sifat asal dan kemungkinan-kemungkinan manusia. Tujuan penciptaan manusia adalah agar. manusia mengabdikan hidup kepada Allah SWT. Dua tugas yang diemban manusia agar tuiuan penciptaannya berhasil adalah menjadi abdullah dan menjadi khalifah ol bumi. Rolasi-relasi yang dilakukan manusia dalam upaya menjalankan tugasnya adalah relas! dengan Tuhan, relasi dengan diri sendirl, relasi dengan sesama manusia, dan relasi dengan alam semesta. Sifat asal manusia atau yang fitrah pada diri manusia adalah cenderung kepada kebaikan. Waiau demikian, manusla pada akhirnya memiliki kemungkinan menjadi baik atau buruk, taqwa atau fujur.
\end{abstract}

Kata kunci: psıkologi Ișami, relasi manusia, sifat asal, kemungkinan manusia.

Fuad Nashori, lahir di Mojokerto 23 Desember. 1970, adalah pengkail serius wacana psikologi Islami. Merulis dan menyunting beberapa buku dengan tema psikologi istami, mempresentasikan makalahmakalah tentang psikologi islami dalam fo. rum ilmiah lokal dan nasional, serta menulis artikel pada berbagai jurnal, majalah dan koran. Saat ini. of Fakultas Psikologi Uli, mengampu matakuliah "Pengantar. Pskologi Islami", "Studi Intensif Psikologi Islami", "Pemikiran dan Peradaban Islam", dan "Psikologl Sosial".

\section{PENGANTAR}

S iapakah, apakah, dan bagaimanakah manusia adalah pertanyaan klasik tentang manusia. Pertanyaan di atas terus-menerus dilontarkan umat manusia sepanjang sejarah. Sampai saat ini orang merasa bahwa jawaban-jawaban terse but belum tuntas.

Tentu saja pertanyaan itu paling tepat apabila diarahkan kepada siapa yang menciptakan manusia. Allah SWT adalah tempat bertanya, karena Dia adalah Sang Pencipta manusia. Apa yang ada dalam al-Qur'an dan al'-Hadits adalah jawaban Allah tentang apa, siapa dan bagaimana sesungguhnya manusia, Di samping memberitakan tentang keberadaan manusia melalui teks, Allanjuga memberitakan siapa manusia lewat manu- 
sia itu sendiri. Dalam bahasa yang populer diungkapkan bahwa cara memahami manusia di samping melalui ayat qauliyah (apa yang tertulis dalam teks), juga melalui ayat kauniyah (apa yang ada of alam semesta dan di dalam diri manusia).

Tulisan ini mencoba mensistematisasi ayat-ayat suci al-Qur'an dan al-Hadits tentang siapa sesungguhnya manusia. Usaha ini merupakan upaya untuk merumuskan dasar-dasar psikologi Islami. Sebagaimana diketahui, salah satu tugas utama psikologi Islami adalah merumuskan bagaimana pardangan Islam tentang manusia. Secara umum dapat dikatakan bahwa pernbicaraan tentang manusia seharusnya mencakup tujuan-tujuan penciptaan manusia, sifat-sifat asal manusia, dan kemungkinan-kemungkinan yang dimiliki manusia.

\section{TUJUAN DAN TUGAS MANUSIA}

Manusia diciptakan Allah SWT dengan tujuan yang mulia, dan sama sekali bukan untuk main-main (OS Ali Imran, 3: 191; OS Shaad, 38: 27). Tujuan Allah menciptakan manusia, tidak lain. adalah agar manusta mengabdikan hidup kepada-Nya. Tuhan berfirman dalam al-Qur'an: "Dan tidaklah AKU ciptakan jin dan manusia kecuali untuk mengabdi Kepada-Ku"(OS. adz-Dzariyaat. 51: 56 ).

Pernyataan di atas dengan tegas menolak pernyataan lain bahwa kehadiran manusia di dunia bersifat alamiah (bahwa kehadiran manusia ada dengan sendirinya dan. karenanya, tidak memiliki tujuan-tujuan khusus). Pernyataan al-Qur'an di atas juga menolak pandangan bahwa manusia diciptakan untuk mengeksploltasi alam semesta dan isinya, termasuk untuk berbuat kerusakan di muka bumi.

Allah SWT, Sang Pencipta (the Creator). menghendaki agar kehidupan manusia di dunia ini diarahkan untuk mengabdi pada-
Nya. Untuk mewujudkan kehendak-Nya itu, Allah telah menancapkan dalam diri manusia kesediaan untuk menyembah-Nya atau mengesakan-Nya (QS. 7: 172), yang secara implisit berisi kesediaan tunduk kepadaNya. Dalam dimensi diri manusia yang paling dalam, dimensi ruh, tertanam keyakinan bahwa Allah-lah pusat kehidupan atau tempat berpaling bagi manusia. Agar dasar-dasar yang terbentuk dalam diri manusia itu terpelihara, maka Allah memberikan bimbingan dengan teks, dalam hal ini al-Qur'an, bagaimana dasar-dasar yang dibangun Allah dalam diri manusia tersebut diamankan atau diwujudkan dalam kehidupan aktual manusia. Bimbingan Tuhan melalui kitab suci adalah cara yang digunakan Tuhan agar manusia selalu dalam posisi meng. abdikan hidup kepada-Nya.

Bagaimana pengabdian kepada Sang Pencipta itu diwujudkan? Agar manusia selalu berada dalam posisi mengabdikan diri kepada Sang Pencipta, maka ada dua tugas hidup yang harus dilakukan menusia.

Pertama, manusia menjadi abdullah atau manusia beribadah (mengabdi) kepadaNya. "Dan tidaklah Aku clptakan iin dan manusia kecuali untuk beribadah kepadaKu' (OS. adz-Dzaariyat, 5: 56). Ibadah dapat diartikan sebagai bentuk penyerahan total kepada Alah dengan melaksanakan apa yang menjadi perintah-Nya dan menjauhi apa yang menjadi larangan-Nya. Dalam pengertian sempit, beribadah adalah melakukan ibadah-ibadah ritual yang dilakukan dengan penuh pemahaman, seperti shalat, zakat, puasa, hail, dzikir. Dengan melakukan perintah-perintah Allah itu, manusia akan cenderung kepada kasih sayang dan akan menghindari kekeilan dan kemungkaran. Shalat, misalnya, dikatakan oleh Allah sebagai dapat mencegah dari kekejian dan kemungkaran (OS al-Ankabut, 29: 45).

Kedua, manusia menjadi khalifah di bumi. "Sesungguhnya Aku hendak menjadikan 
khalifah di muka bumit" (QS. al-Baqarah, 2 30). Allah hendak menjadikan khalifah di muka bumi, dan yang dimaksudkan tidak lain, adalah manusia. Menurut Dawam Rahardjo (1996), khalifahadalah fungsi manusia yang mengemban amanat dari Tuhan (OS. al-Ahzab, 33.72). Apakah amanah Tuhan kepada manusia? Yaitu, memberikan pelayanan terhadap sesama makhluk dengan cara menyebarkan kasih sayang terhadap sesama (rahmatan IIt'alamin) dan ber-amarma'ruf nahi munkar.

Dengan penjelasan di atas, dapat dikatakan bahwa pengabdian kepada Tuhan yang wajib dilakukan manusia terwujud dalam dua jalur, yaitu jalur vertikal dan jatur horisontal. Secara vertika!, manusia memiliki tugas menjadi abdullah (hamba Alah) yang harus menyembah Sang Pencipta dengan melakukan praktik-praktik ibadah tertentu. Secara horisontal, manusia memiliki tugas menjadi khalifąh (wakil) Tuhan di bumi. Dalam tugas kekhalifahannya, manusia bertugas berbuat segala sesuatu yang menghadirkan mantaat bagi dirinya sendiri, sesama manusia, dan alam semesta ini.

Hanya manusia —dan bukan makhiuk lain-yang bersedia dan memiliki kemampuan merealisasikan amanah sebagai waki Tuhan itu. Tentang kesediaan manusia menenma amanah ini digambarkan oleh al-Qur'an bahwa langit, gunung dan bumi menolak amanah itu, namun manusia menerimanya. "Sesungguhnya Kami telah mengemukakan amanar kopada langit, bumi dan gunung-gunung. maka semuanya enggan uniuk memikul amanat itu dan mereka khawatir akan mengkhianatinya, dan dipikullan amanat its olehmanusia"(QS al-Ahzab, 33: 72).

Syarat agar manusia dapat merealisasikannya adalah kemerdekaan atau kebebasan. Dengan kemerdekaan manusia mempunyai kemungkinan melaksanakannya atau tidak melaksanakannya, atau justru melakukan yang sebaliknya, atau melakukannya setengah-setengah (Al-Faruqi, 1988). Apabila manusia dapat melakukannya dengan baik, maka ia mengukuhkan dirinya sebagai makhluk yang berderajat paling tinggi di antara makhluk-makhluk yang berada di alam semesta ini. Rasul dan Nabi adalah contoh-contoh figur manusia yang mampu membuktikan kualitasnya sebagai wakil Tuhan di bumi dengan melakukan amanah sebaik-baiknya. Para penentang Nabi dan Rasul atau orang-orang yang perilakunya bersitat antagonistis terhadap ajaran Rasul dan Nabi (misalnya Fir'aun, Qarun, dan sebagainya) adalah figur-figur yang telah tercatat sebagai wakil Tuhan d bumi yang gagal memenuhi amanat Tuhan.

Dengan adanya kemungkınan manusia melakukan hal yang sebaliknya dari apa yang diperintah Tuhan, maka amanah yang dibebankan kepada manusia sesungguhnya berisiko. Akan tetapi risiko ini tidaklah seberapa besar dibandingkan dengan harapan besaryang mungkin dapat dipenuhinya jika dia diberi kemerdekaan. Tentang risiko memberi amanah kepada manusia, para malaikat pernah mempertanyakannya pada Tuhan. "Mengapa Engkau hendak menjadikan (khalifah) di bumi itu orang yang akan rmembuat kerusakan padanya dan menurnpahkan darah, padahal kami senantiasa bertasbih dengan memuji Engkau dan mensucikan Engkau?" (QS. al-Baqarah, 2: 30). Atas pertanyaan tersebut. Tuhan pun menjawab: "Sesungguhnya Aku mengetahui apa yang lidak Kamu ketahui"(QS al- Baqarah, 2: 30).

Pandangan di atas adalah pandangan dasar tentang manusia. Berbeda dengan psikologi moderen yang memandang manusia lahir ke dunia untuk memenuhi keinginankeinginannya semata (psikoanalisis) atau menyesuaikan diri dengan lingkungannya (behaviorisme), atau justru memandang manusia adalah center of relatedness (yang akhirnya hak kepada manusia untuk meng- 
eksploitasi alam dan lingkungan) sebagaimana pandangan psikologi Humanistik, maka psikologi Islami memandang bahwa kelahiran manusia ke dunia membawa tujuan tertentu, yaitu agar manusia mengabdikan hidup kepada Sang Pencipla. Misi utama yang diemban manusia dalam rangka mengabdikan hidup adalah menjadi khalifah (wakil Tuhan) di bumi dengan memberikan pelayanan terhadap sesama

\section{RELASI-RELASI MANUSIA}

Untuk meneguhkan perannya sebagai abdullah dan sebagai khalifah di bumi. manusia melakukan empat macam relasi. Relasi-relasi yang dijalani manusia ini adalah wujud dari amanah yang harus diembantya. Amanat yang dibebankan kepada manusia tidak mengenal batas. Tanggung jawab itu meliputi seluruh atam semesta. Dikatakan oleh Ismail al-Faruqi (1988) bahwa seluruh umat manusia adalah objek tindakan moral manusia; seluruh bumi dan langit adalah panggungnya. Manusia bertanggung jawab atas segala sesuatu yang terjadi di alam raya, dalam setiap sudutnya yang paling jauh sekalipun. Karenanya tanggung jawab manusia bersifal universal.

Dalam melaksanakan tanggung jawab itu, manusia memiliki kemerdekaan atau kebebasan untuk melakukannya secara positif alau secara negatif. Bila marusia melakukanfya secara positit, maka amanah dilakukan dengan baik. Apabila manusia melakukannya secara negatif, maka amanah dilakukan secara buruk atau gagal dilakukan manusia.

Dalam relasi dengan Tuhan (hablumminallah), manusia memenuhi kewajiban beribadah kepada-Nya (OS. al-Dzariyaat, $51-56$ ) atau menjadi ingkar (kafir) dan syirik kepada-Nya (QS. an-Nisa', 4: 48). Bila manusia melakukan relasi ini secara baik, maka huburngan manusia dengan-Nya menjadi baik; dan Alah akan berkenan memberikan apa yang menjadi kebutuhan-kebutuhan ma nusia. Bila manusia melakukan relasi ini secara buruk, maka hubungan manusia dengan-Nya semakin jauh: dan Alah akan me limpahkan laknat atasnya.

Dalam relasi dengan diri sendiri (hablumminan-nals), manusia memperoleh kesadaran tentang diri serta memilit hal-hal yang terbaik untuk diri sendiri atau mengumbar natsu rendah (OS. 38: 6). Bila manusia selalu memperhatikan panggilan-panggilan dari dalam dirinya, dari hati nuraninya, maka mereka negafit melakukan relasi secara positif dengan dirinya sendiri. Sebaliknya, bila manusia mengumbar nafsu rendah, ia memilih rełasi intern diri secara negatif.

Dalam relasi dengan sesama manusıa (hab/um-minan-nas). manusia dapa: menbina silaturrahmi (QS an-Nisa', 4:1) dan beramar makruf nahi munkar (QS Ali imran, 3: 110) atau memutuskan silaturrahmi (QS. Yusuff 12: 100) dan berbuat dzalim serhadap orang lain. Bila manusia mélakukan relasi ini secara posit it. maka hubungan dengan sesama akan menjadi dekat secara hakiki. Sebaliknya, bila manusia melakukan relasi antar sesama ini secara negatif, maka hubungan antar manusia akan menjauh secara hakiki.

Dalam relasi dengan alam (hablum.minaf-'alami). manusia memarfaatkan dan melestarikan alam dengan sebaik-baiknya (QS. Huud, 11: 6) atau menimbulkan kerusakan alam (OS. ar-Ruum, 30:41). Bila manusia melakukan relasi secara positif dengan alam semesta, maka eksistensi alam semesta terpelihara. Sebaliknya, bila manusia melakukan relasi dengan alam semesta itu secara negatit, maka eksistensi alam akan menjadi terancam rusak dan bahkan punah.

Relasi-relasi tersebut dapat membaik dan memburuk, disebabkan oleh faktorfaktor internal dan eksternal. Secara internal, relasi akan membaik bila manusia dapat 
menghayati tugas-tugas sebagai abdullah dan khalifah di bumi secara baik. Relasi akan memburuk bila penghayatan akan tugas-tugas of atas kurang.

Tidak kurang dari itu, kualitas relasi akan meningkat atau menurun karena faktor-faktor eksternal. Faktor ekstemal ini antara lain berupa penghalang-penghalang hubungan. Dalam hubungan jenis apapun ada kekuatan eksternal yang menghalangi, baik penghalang yang bersifat tetap maupun penghalang yang bersifat insidental. Penghalang yang bersifat tetap adalah penghalang yang berasai dari kekuatan yang dengan sengaja mengerahkan dan mengarahkan hidupnya untuk merusak hubungan-hubungan positif yang dibangun manusia, yang notabene dilakukan iblis dan setan. Sementara penghalang-penghalang yang bersifat insidental datang dari diri manusia itu sendiri, manusia yang lain, jin, dan dari kekuatan alam.

Bukti bahwa setan dan iblis menjadi penghalang yang bersitat tetap bagi kesuksesan manusia sebagai abdullah dan khalifah diterangkan al-Qur'an. "Karana Engkau telah menghukum saya tersesat, saya benar-benar akan (menghalang-halangi) mereka dari jalan Engkau yang lurus, kemudian saya akan mendatangi mereka dari muka dan dari belakang mereka, dari kanan dan dari kiri mereka. Dan Engkau tidak akan mendapati mereka bersyukur (taat)' (OS. alAraaf. 7: 16-17).

\section{SIFAT ASAL DAN KEMUNGKINAN-KE- MUNGKINAN MANUSIA}

Bagaimana sifat asal manusia? Baik atau baik-buruk? Dalam Simposium Nasional Psikologi Is/ami(1994) muncul dua macam pendapat. Pendapat pertama mengungkapkan pada dasarnya sebelum dilahirkan manusia hanya mempunyai sifat asal kebaikan. Pandangan kedua meyakini bahwa di samping sitat asal kebaikan, manusia juga mempunyai fitrah (sifat asal) untuk mementhi dorongan kesenangan (fujur).

Tentang sifat asal manusia yang hanya cenderung kepada kebaikan, maka kita dapat memakai dua dasar. Pertama, ketika berada di alam azali Tuhan berkenan menghembuskan Ruh-Nya kepada manusia (QS. al-Hijr 15: 29). Itu berarti dalam diri manusia ada Rihh Tuhan (Al-Faruqi menyebutnya sebagai "nafas" Tuhan; yang menjadikan sebagai makhluk bercitra Tuhan). Ruh Tuhan inilah yang selalu bersarang dalam diri manusia. Dengan Riuh Tuhan itu manusia mempunyai keterikatan dengan kebaikan dan ke benaran sejati (baca: Tuhan). Karena pusat keterikatannya adalah dengan Tuhan, maka Al-Faruqi (1988) menyebut manusia sebagai homo relligiosus, yailu makhluk yang kesadarannya terfokus pada kehadiran Tuhan yang bersifat sentral.

Argumen kedua yang sering dipakai untuk menunjukkan bahwa manusia diciptakan dalam keadaaan mula baik adalah kesaksian manusia pada Tuhan pada jaman azali (Ancok \& Suroso, 1995). Allah mengambil kesaksian terhadap manusia: "Bukankah Aku ini Tuhanmu?" Jawab mereka: "Betul (Engkau Tuhan kami), kami menjadi saksl." (QS. al-A'raf, 7: 172). Ayat ini menegaskan bahwa sebelum kelahirannya, manusia hanya punya satu macam kesaksian. Kesaksian itu adalah pengakuan atau kesaksian akan eksistensi Tuhan.

Dari sini dapat disimpulkan bahwa yang fitrah, yaitu "apa yang menjadi bawaannya sejak lahir", dalam diri manusia hanyalah kebaikan. Secara tekstual pernyataan ini sesuai dengan firman Alah: Dan kami menciptakan manusia dalam keadaan yang sebaik-baiknya (QS. at-Tiin, 95: 4).

Sementara terhadap pertanyaan adakah manusia mempunyai sifat asal cenderung kepada syahwat (baca; sifat buruk), muncui perbedaan interpretasi. Pihak yang mem- 
percayai bahwa manusia lahir dengan potensi untuk memuaskan kesenangan menandaskan bahwa Allah membekali manusia dengan syahwat yang menjadikannya mengharapkan hadirnya kesenangan hidup di dunia. Tuhan berfirman: "Dijadikan indah pada (pandangan) manusia kecintaan kepada apa-apa yang diingini, yaitu wanita-wanita, anak-anak, harta yang banyak dari jenis emas, perak, kuda piiihan, binatang-binatang ternak, dan sawah ladang. Mulah kesenangan hidup di dunia". Secara implisit dapat dikelahui bahwa hal-hal yang menjadikan kesenangan bagi manusia adalah sesuatu yang berada di luar diri manusia.

Menurut penulis, manusia sendiri se. sungguhnya tidak pernah diberi sifa! buruk oleh Tuhan. Dalam diri manusia memang dihiaskan kebutuhan untuk mendapatkan kesenangan. Kebutuhan ini sendiri sesungguhnya bersifat netral, dalam pengertian iz dapat dilakukan dengan cara yang baik dan dapat dilakukan dengan cara yang buruk. Kecenderungan untuk memenuhi kebutuhan ini sangat tergantung kepada lingkungan yang membentuk manusia.

Penjelasan tentang sifat asal ini sangat penting sebagai dasar penanganan persoalan manusia. Kalau kita menggunakan dasar pemikir an bahwa manusia itu baik (mempunyai kecenderungan kepada kebaikan/kebenarani dan bila suatu saat manusia berada dalarn kesulitan atau terbelit persoalan besar. maka ada optimisme ke arah perbaikan hidup manusia.

Pandangan di atas sekaligus merupakan penolakan terhadap pandangan psikoanalisis (bahwa manusia mempunyai kecenderungan ke arah pemuasan nafsu, kecenderungan buruk), behaviorisme (bahwa manusia mernpunyai sifat asal netral), atau psikologi humanistik (bahwa mannusia adalah baik; tapi bukan kebaikan dalam bimbingan Tuhan).
Sungguh pun manusia hanya memiliki sifat asal yang baik, ia tetap dapat menjadi orang yang buruk. Sebuah hadis yang terkenal mengungkapkan: Setiap anak dilahirkan dalam keadaan suci; orangtuanyalah yang menjadikannya Yahudi, Nasrani atau Majusi. Manusia (anak) diciptakan dalam keadaan baik. tetapi ketika tumbuh kembang ia dapa! menjadi manusia yang sanga! buruk. manusia yang salah urus dapat turnbuh menjadi makhluk yang berbahaya dari binatang. Dalam al-Qur'an, Allah bertirman: Dan Karm ciptakan manusia daiam keadaan yang sebaik-baiknya: kernudian kami tempatkan mereka ke tempat yang serendahrendahnya (QS at-Tiin. 4-5). Datarn posisi sebagai makhluk yang jatuh, yang akhirnya menempati tempat yang paling buruk, manusia dipandang lebih buruk dari binałang: lebih culas, lebih licik, lebih rakus, dan sebagainya. Terangkanlah kepada-Ku tentang orang yang menjadikan hawa nafsunya sebagaj Tuhannya. Maka apakah karnu akan menjadi pengendaii atasnya? Apakah kamu mengira kebanyakan mereka itu mendengar dan memaharni? Mereka ilu tak lain hanyalah seperti binatang ternak, bahkan mereka iebih sesat jalannya (dari binatang ternak itu) (QS. al-Furqan, 25: 43-44).

Dari sıni dapat dikalakan bahwa manusia memiliki rentang kemungkinan yang sang at luas. Manusia dapat tumbuh menjadi makhluk yang sebaik-baiknya (merniliki keimanan, ilrnu pengetahuan, ketrampilan, dan sebagainya yang bermanfaat) dan dapat pula tumbuh menjadi makhluk yang seburukburuknya. Dalam ungkapan lain, manusia dapat menjadi makhluk yang memilih jalan takwa dan dapat pula memilih jalan fujur (sesat). la bebas untuk menentukan sendiri apakan ia akan memilih untuk meneruskan pilihan-pilihan hidupnya atau tjak. Dalam situasi seperti ini, al-Qur'an menggambarkan bahwa manusia memiliki kebebasan untuk memilih antara kebaikan dan keburuk- 
an. la bebas memilih menjadi orang yang bertakwa atau orang fujur (menyimpang). Maka Dia mengilhamkan kepada jiwa itu jalan keburukan dan jalan kebaikan (QS. alSyam, 91: 8).

\section{PENUTUP}

Penjelasan-penjelasan tentang hal-hal mendasar lain tentang manusia (seperti masalah potensi dan keunikan manusia) akan disampaikan dalam tulisan lain. $\square$

\section{DAFTAR PUSTAKA}

Al-Faruqi, I.R. 1988. Tauhid. Bandung: Pustaka.

Ancok, D. \& Suroso, F.N. 1995. Psikologi Islam. Cetakan Kedua. Yogyakarta: Pustaka Pelajar.

Asy'ari, S\& Yusuf, R. 1984. Indeks AJ-Qur'an. Bandung: Penerbit Pustaka.

Bastaman, H.D. 1995, Integrasi Psikologi dengan Islam. Editor: Fuad Nashori. Yogyakarta: Yayasan Insan Kamil \& Pustaka Pelajar.

DepartemenAgama Rl. 1982. Al Qur'andan Terjemahannya. Jakarta: Departemen Agama RI.

Hadhiri. C. 1993. Kasifikasi KandunganAlQur'an. Jakarta: Gema Insani Press.
Nashori, F. 1996. "Peta Pemikiran Psikologi Islami: Upaya Memahami Problem, Te ma dan Agenda Kerja Pengembangan Psikologi Islami". Makakah disampaikan dalam Seminar Nasional Psikoterapi is. lami, UMM, Malang, 1-3 November 1997.

- 1996. "Selayang Pandang Psikologi Islami". Makalah disampaikan dalam Simposium Nasional Psikologi Islami, Unpad, Bandung, 14-15 Desember 1997.

—. 1997. "Mengapa Kita Perlu Mengembangkan Psikologi Islami?" Makalah disampaikan dalam kegiatan Diskusi Psikologi Islami, KMP-UGM \& Yayasan insan Kamil, Yogyakarta, 7 Maret 1997.

Rahardjo, M D. 1996. EnsiklopediAl-Qur'an. Jakarta: Penerbit Paramadina.

Shihab, M.Q. 1994. "Manusia dalam Pandangan al-Qur'an", Makalah disampaikan dalam Simposium Nasional Psikalogi islami, yang diadakan Fakultas Psikologi UMS, Surakarta, 11-13 November 1996.

Tim Perumus. 1994. "Rumusan Hasil Simposium Nasional Psikologi Islami". Dalam Simposium Nasional Psikologi Islami 1994, Fakultas Psikoogi UMS, Surakarta, 11-13 November 1994. 